\title{
Poverty and Community-Acquired Antimicrobial Resistance with Extended-Spectrum $\beta$-Lactamase- Producing Organisms, Hyderabad, India
}

\author{
Marcella Alsan, Nagamani Kammili, Jyothi Lakshmi, Anlu Xing, Afia Khan, \\ Manisha Rani, Prasanthi Kolli, David A. Relman, Douglas K. Owens
}

The decreasing effectiveness of antimicrobial agents is a global public health threat, yet risk factors for communityacquired antimicrobial resistance (CA-AMR) in low-income settings have not been clearly elucidated. Our aim was to identify risk factors for CA-AMR with extended-spectrum $\beta$-lactamase (ESBL)-producing organisms among urbandwelling women in India. We collected microbiological and survey data in an observational study of primigravidae women in a public hospital in Hyderabad, India. We analyzed the data using multivariate logistic and linear regression and found that $7 \%$ of 1,836 women had bacteriuria; $48 \%$ of isolates were ESBL-producing organisms. Women in the bottom 50th percentile of income distribution were more likely to have bacteriuria (adjusted odds ratio $1.44,95 \% \mathrm{Cl}$ 0.99-2.10) and significantly more likely to have bacteriuria with ESBL-producing organisms (adjusted odds ratio 2.04, $95 \% \mathrm{Cl} 1.17-3.54)$. Nonparametric analyses demonstrated a negative relationship between the prevalence of ESBL and income.

ntimicrobial resistance (AMR) is a growing global Apublic health threat that could reverse decades of progress in increasing longevity around the world (1). The rapid pace of AMR spread coupled with a shortage of novel antimicrobial agents has led the World Health Organization (WHO) to warn of a "postantimicrobial era" (2). By

Author affiliations: National Bureau of Economic Research, Cambridge, Massachusetts, USA (M. Alsan); Stanford University, Stanford, California, USA (M. Alsan, A. Xing, D.A. Relman, D.K. Owens); Veterans Affairs Palo Alto Health Care System, Palo Alto, California, USA (M. Alsan, A. Xing, D.A. Relman, D.K. Owens); Gandhi Medical College and Hospital,

Secunderabad, India (N. Kammili, J. Lakshmi, M. Rani); University of Chicago, Chicago, Illinois, USA (A. Khan); Guntur Medical College and Hospital, Guntur, India (P. Kolli)

DOI: https://doi.org/10.3201/eid2408.171030
2050, deaths attributable to AMR could exceed 10 million per year, more than the number of deaths from cancer and traffic accidents combined, while costing the global economy US \$60-\$100 trillion of economic output (3). Most policy recommendations for curtailing AMR are tailored to wealthy nations; however, the threat of AMR is also severe for poorer countries $(4,5)$. Infectious diseases are still common causes of illness and death in such settings, and the availability of second- or third-line therapies is limited $(6,7)$. Yet, detailed estimates of the prevalence of AMR in developing countries are limited and often rely on samples from returning travelers or in-country patients receiving care for suspected infectious diseases. These data point to an alarming rate of community-acquired AMR (CA-AMR) in extended-spectrum $\beta$-lactamase (ESBL)-producing organisms, including in Hyderabad, India, the setting of this study $(8-11)$. Such trends are of international concern given the possibility for AMR pathogens and genetic elements to spread across political and geographic boundaries.

Because of the lack of detailed data from developing countries, empirical work on predictors of CA-AMR is generally limited to responses from wealthy countries or cross-country comparisons. These studies generally document robust positive relationships between antimicrobial drug use, healthcare provider contacts, and the prevalence of AMR (12-15). These strong links have led to the hypothesis that growing drug resistance in developing countries is attributable to rising incomes, which increase demand for many health products, including antimicrobial drugs (1618). Yet, other factors that place the poor at greater risk for CA-AMR might be more pronounced in developing countries. First, the poor are more likely to be exposed to infectious agents from other humans and are at higher risk for illness because of malnutrition and immunodeficiency (4). Second, the poor are more likely to experience subinhibitory doses of antimicrobial agents because of shorter courses 
of treatment, sharing medication, or expired or low-quality drugs (19-22). Third, the poor may be more likely to acquire resistant pathogens or AMR genetic elements in their food or water, leading to CA-AMR (23-25).

To clarify the prevalence of and risk factors for CAAMR and the specific relationship with poverty for individual persons in a developing country context, we prospectively collected data on 1,836 primigravidae women in a large public hospital in Hyderabad, India, over 12 months. To reduce the probability that AMR was acquired through a healthcare contact or activity, our study population consisted of women who were carrying a pregnancy to term for the first time and had never been hospitalized for a pregnancy. We focused on ESBL-producing organisms because findings by other researchers demonstrated rising rates of community-acquired infections associated with these organisms $(8-11,15)$. We complemented our microbiological sample collection with a detailed survey on sociodemographic information and assessed AMR risk factors using the US Demographic and Health Surveys tool AMR Module for Population-Based Surveys $(26,27)$.

\section{Methods}

\section{Study Design}

The design was a cross-sectional observational study of women in Hyderabad, India, carrying a pregnancy to full term for the first time. The study was approved by the Indian Council of Medical Research (ICMR), the Institutional Review Board of Gandhi Medical College and Hospital, and the Administrative Panel for the Protection of Human Subjects (Institutional Review Board) of Stanford University.

\section{Setting and Participants}

We conducted the study at Gandhi Medical College and Hospital, a large public teaching hospital in Hyderabad that provides free healthcare for all. We surveyed first-time pregnant women seeking antenatal care from October 1, 2015, through September 29, 2016. We identified eligible patients from the outpatient clinic roster. Patients were deemed eligible if they were $\leq 40$ years of age, pregnant for the first time, and had not been interviewed on a prior visit. After obtaining informed consent, a team member interviewed patients in a quiet research office. One woman with an incomplete survey was omitted. Results are robust to her inclusion.

\section{Data Sources/Measurement}

We performed urine culture and bacterial identification using ChromID CPS3 agar and the VITEK-2 system (both from BioMerieux, Marcy l'Etoile, France). We performed antimicrobial susceptibility testing and interpretations, including ESBL screening using theVITEK-2 ESBL test (identification and antimicrobial susceptibility pattern), in accordance with guidelines from the Clinical and Laboratory Standards Institute (online Technical Appendix, https:// wwwnc.cdc.gov/EID/article/24/8/17-1030-Techapp1.pdf). We diagnosed bacteriuria when there were $\geq 10^{5} \mathrm{CFU}$ of a single bacterial strain per milliliter of urine or when $\geq 2$ different colony types were present and 1 had a colony count of $\geq 10^{5} \mathrm{CFU} / \mathrm{mL}$.

A trained onsite investigator conducted a structured interview at the time of the antenatal visit using a questionnaire based on the Demographic and Health Surveys tool AMR Module for Population-Based Surveys (27). We queried patients on their usual and current residence, occupation, husband's occupation, household income, religion, caste, education level, dietary and hygiene practices, and recent nonvitamin tablet consumption. Many of the women did not understand the original question about antimicrobial drug use, so we used ingestion of any tablet other than a vitamin as an upper bound on recent antimicrobial drug ingestion. Study staff also directed women to use the cleancatch urine sample technique. We sent all laboratory test results to the patient's healthcare provider for further action. Definitions of variables included in the analysis are provided in the online Technical Appendix.

\section{Statistical Methods}

We performed 3 analyses to identify predictors of bacteriuria or growth of an ESBL-producing organism. First, we assessed univariate relationships among sociodemographic, clinical, and environmental exposures and bacteriuria or CA-AMR caused by ESBL-producing organisms; we used $t$-tests for continuous outcomes and $\chi^{2}$ tests for categorical outcomes.

Guided by the results from an unadjusted analysis, which demonstrated poverty as a significant predictor of the outcome, we used logistic regression to estimate the association between income and bacteriuria, as well as between income and bacteriuria from ESBL-producing organisms. The model also included background characteristics that might influence bacteriuria or AMR, such as respondents' education level. We included age and Hindu religion because results for both were significant in 1 of the 2 univariate analyses. We included prior hospitalization and history of abortion because these variables reflect prior exposure to the inpatient medical system, which has been shown to be a risk factor for AMR in industrialized countries (28). We did not include previous antimicrobial drug use in our main model, even though it is included in a related analysis (online Technical Appendix Figure 1). Because few study participants reported any tablet ingestion in the last 30 days, the confidence intervals were very large (13). The reported results on income were not sensitive to the inclusion of tablet ingestion. 
Next, we used linear regression to assess the nonparametric relationship between income and CA-AMR from ESBL-producing organisms. Specifically, we divided income into quartiles and included these quartiles in the linear regression along with the covariates previously described and used in the logit regression. For the 59 respondents missing income information ( $3.2 \%$ of the sample), we generated predicted income values from husband's occupation, education level, age at marriage, religion, and season. We normalized income per 10,000 rupees for graphing purposes. We performed the same analysis with the missing income values dropped rather than substituted with predicted values (online Technical Appendix Figure 2).

\section{Results}

The average age of women in the study was 21.8 years, slightly higher than the national average age at the time of first birth, which is 19.9 years (Table 1). Approximately one third $(631 / 1,836)$ of the women surveyed were anemic; $862(46.5 \%)$ were underweight and $288(15.6 \%)$ reported a previous abortion, although none had previously carried a pregnancy to term. Forty-seven $(2.6 \%)$ reported taking any nonvitamin tablet in the last 30 days.

A total of 126 respondents had significant bacterial growth in their urine, defined as $\geq 10^{5} \mathrm{CFU} / \mathrm{mL}$. Gramnegative rods accounted for 107/126 (85\%) of the isolates, including Escherichia coli $(\mathrm{n}=75)$, Klebsiella $(\mathrm{n}=28)$,
Sphingomonas $(\mathrm{n}=2)$, Enterobacter $(\mathrm{n}=1)$, and Citrobac$\operatorname{ter}(\mathrm{n}=1)$. The remaining 19 isolates were gram-positive organisms, including Staphylococcus, Streptococcus, and Enterococcus; 1 organism was unknown. Of the ESBL isolates, $82 \%$ were E. coli and $18 \%$ were $K$. pneumoniae. At this level of prevalence, the study had $80 \%$ power to detect differences of $\approx 0.10$ in the proportion of categorical variables and $\approx 0.75$ in continuous variables.

Women with significant bacteriuria did not substantially differ from those without bacteriuria in terms of age, age at time of marriage, or educational background (Table 1). Prevalence of anemia, dysuria, fever, and low weight were also not statistically different between the 2 groups, nor were hospitalizations within the previous year or use of nonvitamin tablets over the previous 30 days. Hindu participants were less likely to have high levels of bacteriuria than were those from other religious groups $(p=0.02)$, although we did not find a significant relationship between ESBL and religion. Women with bacteriuria were significantly more likely to fall in the lower half of the income distribution: $60.0 \%$ of women with bacterial growth had household incomes below the sample median, compared with $50.2 \%$ of women with no bacterial growth $(p=0.04)$.

We compared women with ESBL-producing bacteria with women without these bacteria (Table 2). Similar to the findings regarding bacteriuria, the demographic and clinical characteristics of women with ESBL-producing

\begin{tabular}{|c|c|c|c|c|}
\hline Characteristic & $\begin{array}{c}\text { All respondents, } \\
\mathrm{N}=1,836\end{array}$ & $\begin{array}{c}>10^{5} \mathrm{CFU} / \mathrm{mL} \text { bacteria in } \\
\text { urine, } \mathrm{n}=126\end{array}$ & $\begin{array}{c}\text { No bacteria in urine, } \\
n=1,710\end{array}$ & $p$ value \\
\hline \multicolumn{5}{|l|}{ Sociodemographic characteristics } \\
\hline Mean age, y (SD) & $21.81(2.95)$ & $22.05(3.02)$ & $21.79(2.94)$ & 0.35 \\
\hline Mean age at marriage, y (SD) & $20.31(2.87)$ & $20.29(3.22)$ & $20.31(2.84)$ & 0.93 \\
\hline Low income, no. (\%)† & $932(50.8)$ & $75(60.0)$ & $857(50.2)$ & 0.04 \\
\hline Less than secondary education, no. (\%)‡ & $322(17.5)$ & $23(18.4)$ & $299(17.5)$ & 0.81 \\
\hline Hindu, no. $(\%) \S$ & $1,228(66.9)$ & $72(57.6)$ & $1,156(67.8)$ & 0.02 \\
\hline \multicolumn{5}{|l|}{ Clinical characteristics, no. (\%) } \\
\hline Anemia & $631(33.6)$ & $48(38.4)$ & $583(34.2)$ & 0.38 \\
\hline Low weight of mother & $862(46.5)$ & $61(48.8)$ & $801(47.0)$ & 0.78 \\
\hline Previous abortion & $288(15.6)$ & $18(14.4)$ & $270(15.8)$ & 0.80 \\
\hline Previous hospitalization & $159(8.7)$ & $13(10.4)$ & $146(8.6)$ & 0.51 \\
\hline Tablet during last 30 days\# & $47(2.6)$ & $5(4.0)$ & $42(2.5)$ & 0.25 \\
\hline Dysuria** & $220(12.0)$ & $16(12.8)$ & $204(12.0)$ & 0.78 \\
\hline Fever & $84(4.6)$ & $5(4.0)$ & $79(4.6)$ & 1.00 \\
\hline \multicolumn{5}{|c|}{ Environmental and hygiene-related characteristics, no. (\%) } \\
\hline Household does not treat water & $1,339(72.9)$ & $93(74.4)$ & $1,246(73.0)$ & 0.92 \\
\hline Household sewage not piped & $90(4.9)$ & $8(6.4)$ & $82(4.8)$ & 0.39 \\
\hline Respondent strictly vegetarian & $142(7.7)$ & $8(6.4)$ & $134(7.9)$ & 0.73 \\
\hline Handwashing $<5$ times/d & $345(18.8)$ & $26(20.8)$ & $319(18.7)$ & 0.64 \\
\hline \multicolumn{5}{|c|}{$\begin{array}{l}\text { *Bold indicates statistical significance. } p \text { values were derived from } t \text {-test (for mean age variables) or } x^{2} \text { test (for categorical variables). CFU, colony- } \\
\text { forming units. } \\
\text { †lncome is total household income in previous } 30 \mathrm{~d} \text {; low income is an indicator variable for below the } 50 \text { th percentile of income. } \\
\text { fLess than secondary education is an indicator variable for whether the participant reported no schooling or primary-only schooling. } \\
\text { §Hindu is an indicator variable for Hindu religion. } \\
\text { THHospitalization in the previous } 12 \text { mo. } \\
\text { \#Tablet means any tablet other than a vitamin taken by the respondent in the } 30 \mathrm{~d} \text { before interview. We used the term "tablet" because "antimicrobial" } \\
\text { was unclear for many respondents. } \\
\text { **For dysuria, an answer of "don't know" was coded as } 0 \text { (no). }\end{array}$} \\
\hline
\end{tabular}


Table 2. Unadjusted relationship between community-acquired antimicrobial drug resistance caused by ESBL-producing organisms and sociodemographic, clinical, and environmental characteristics for pregnant women in Hyderabad, India*

\begin{tabular}{|c|c|c|c|c|}
\hline Characteristic & $\begin{array}{c}\text { All respondents, } \\
\mathrm{N}=1,836\end{array}$ & $\begin{array}{c}\text { ESBL present, } \\
\mathrm{n}=60\end{array}$ & $\begin{array}{c}\text { No ESBL present, } \\
n=1,776\end{array}$ & $p$ value \\
\hline \multicolumn{5}{|l|}{ Sociodemographic characteristics } \\
\hline Mean age, y (SD) & $21.81(2.95)$ & $22.65(3.48)$ & $21.78(2.93)$ & 0.06 \\
\hline Mean age at marriage, y (SD) & $20.31(2.87)$ & $20.57(4.19)$ & $20.30(2.82)$ & 0.63 \\
\hline Low income, no. (\%)† & $932(50.8)$ & $40(66.7)$ & $892(50.4)$ & 0.01 \\
\hline Less than secondary education, no. (\%)‡ & $322(17.5)$ & $10(16.7)$ & 312 (17.6) & 1.00 \\
\hline Hindu, no. $(\%) \S$ & $1,228(66.9)$ & $36(60.0)$ & $1,192(67.3)$ & 0.27 \\
\hline \multicolumn{5}{|l|}{ Clinical characteristics, no. (\%) } \\
\hline Anemia & $631(33.6)$ & $19(31.7)$ & $612(34.6)$ & 0.78 \\
\hline Low weight of mother & $862(46.5)$ & 32 (53.3) & $830(46.9)$ & 0.36 \\
\hline Previous abortion & $288(15.6)$ & $11(18.3)$ & $277(15.6)$ & 0.59 \\
\hline Previous hospitalization $\rrbracket$ & $159(8.7)$ & $6(10.0)$ & $153(8.6)$ & 0.64 \\
\hline Tablet during last 30 days\# & $47(2.6)^{\prime}$ & $3(5.0)$ & $44(2.5)$ & 0.20 \\
\hline Dysuria** & $220(12.0)$ & $7(11.7)$ & $213(12.0)$ & 1.00 \\
\hline Fever & $84(4.6)$ & $2(3.3)$ & $82(4.6)$ & 1.00 \\
\hline \multicolumn{5}{|c|}{ Environmental and hygiene-related characteristics, no. (\%) } \\
\hline Household does not treat water & $1,339(72.9)$ & $45(75.0)$ & $1,294(73.1)$ & 0.77 \\
\hline Household sewage not piped & $90(4.9)$ & $4(6.7)$ & $86(4.9)$ & 0.53 \\
\hline Respondent strictly vegetarian & $142(7.7)$ & $2(3.3)$ & $140(7.9)$ & 0.32 \\
\hline Handwashing $<5$ times/d & $345(18.8)$ & $15(25.0)$ & $330(18.6)$ & 0.24 \\
\hline \multicolumn{5}{|c|}{$\begin{array}{l}\text { *p values were derived from } t \text {-test (for mean age variables) or } x^{2} \text { test (for categorical variables). Bold indicates statistical significance. ESBL, extended- } \\
\text { spectrum } \beta \text {-lactamase. } \\
\text { tIncome is total household income in previous } 30 \mathrm{~d} \text {; low income is an indicator variable for below the } 50 \text { th percentile of income. } \\
\text { †Less than secondary education is an indicator variable for whether the participant reported no schooling or primary-only schooling. } \\
\text { \$Hindu is an indicator variable for Hindu religion. } \\
\text { TH } \\
\text { \#Tabpitalization in previous } 12 \text { mo. } \\
\text { for many reans any tablet other than a vitamin taken by the respondent in the } 30 \mathrm{~d} \text { before interview. We used "tablet" because "antimicrobial" was unclear } \\
\text { **For dysuria, an answer of "don't know" was coded as } 0 \text { (no). }\end{array}$} \\
\hline
\end{tabular}

bacteria were not substantially different from those of women without these bacteria. However, $66.7 \%$ of women with ESBL-producing bacteria had household income below the median versus $50.4 \%$ of women without these bacteria, a significant finding $(\mathrm{p}=0.01)$.

Figure 1 shows the adjusted odds ratios $(\mathrm{aOR})$ and 95\% CIs for the relationships between respondent characteristics and the 2 study outcomes: any significant levels of bacteriuria or bacteriuria with ESBL-producing organisms. Being in the bottom half of the income distribution was associated with a greater likelihood of significant bacteriuria (aOR 1.44, 95\% CI 0.99-2.10) and a greater likelihood of bacteriuria caused by ESBL-producing organisms (aOR 2.04, 95\% CI 1.17-3.54). The only other predictor of ESBL that achieved statistical significance was age; higher age was positively associated with ESBL-producing organisms (aOR 1.09, 95\% CI 1.02-1.18).

Nonparametric relationships between income and bacteriuria (Figure 2, panel A) and between income and ESBL (Figure 2, panel B), adjusted for the same set of covariates as in Figure 1, demonstrate a robust negative relationship between income quartile and both outcome variables. The poorest quartile had a predicted prevalence of $8.67 \%(95 \%$ CI $6.59 \%-10.73 \%$ ) for significant bacteriuria and $4.68 \%$ (95\% CI $3.23 \%-6.13 \%$ ) for bacteriuria caused by ESBL organisms. When we restricted the analysis to women who had substantial bacterial growth in the urine, we observed a similar ESBL-income gradient (online Technical Appendix Figures 3, 4). This relationship did not occur between income and other potentially correlated outcome variables, such as hospitalization, past abortion, and tablet consumption (online Technical Appendix Figure 5).

We estimated a model that included a first- and second-order term in income to investigate nonlinearities in the relationship between income and CA-AMR (online Technical Appendix Figure 6). This approach was motivated by the observation of a slightly greater prevalence of ESBL bacteruria in the fourth versus the third income quartile (Figure 2, panel B). The coefficient on income was negative and significant $(p=0.001)$, consistent with the results from the other models. The coefficient on income squared was positive and significant $(p<0.001)$, which implies a Ushaped function relating AMR and income. However, we calculated that the lowest ESBL risk occurs at an income of 24,000 rupees, which corresponds to roughly the 95th percentile of income in our sample. This finding implies that, for most women we surveyed, the probability of ESBL declines as household income rises.

\section{Discussion}

This study produced 4 main results. First, $7 \%$ of women $(126 / 1,836)$ had bacteriuria and $\approx 48 \%$ of their urine isolates were ESBL. This finding is striking for 2 reasons: almost none of these women reported recent antimicrobial 


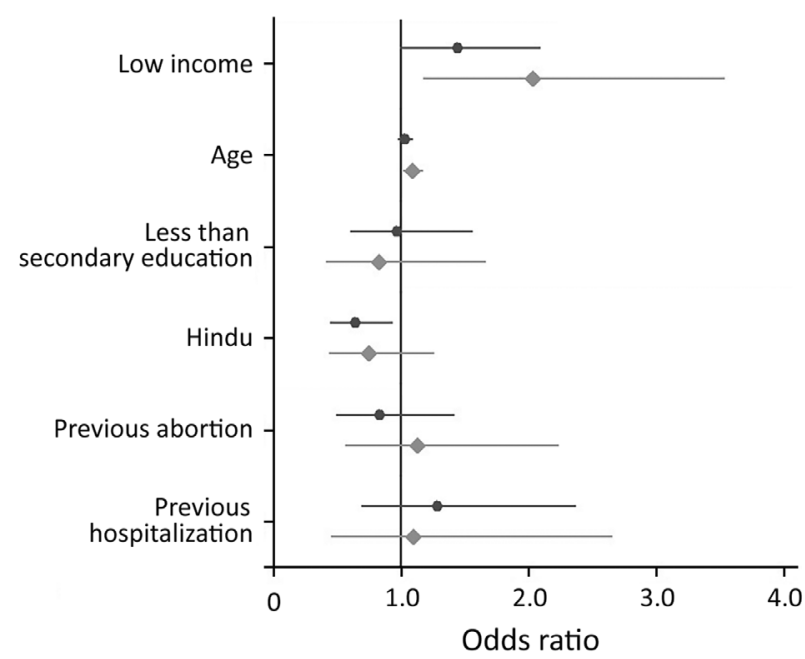

Figure 1. Adjusted odds ratios of bacteriuria and communityacquired antimicrobial resistance with ESBL-producing organisms by selected predictive variables for pregnant women in Hyderabad, India. Black dots represent odds ratios for bacterial growth in urine culture; lines indicate $95 \%$ Cls. Gray diamonds represent odds ratios for ESBL-producing organisms; lines indicate $95 \% \mathrm{Cls}$. The vertical line shows odds ratio $=1.0$. ESBL, extended-spectrum $\beta$-lactamase.

drug use, and the sample (women carrying pregnancies to full term for the first time) was specifically chosen to mitigate healthcare-associated exposures that increase the risk for multidrug-resistant organisms. Second, women who had ESBL-producing organisms were less likely than those without these organisms to have been hospitalized recently or to report recent ingestion of nonvitamin tablets, thereby excluding some of the major correlates of AMR among wealthier populations. Third, the most robust predictor of whether women had clinically significant bacteriuria, including with ESBL-producing organisms, was household income. Outside of the top 5\% of incomes, this relationship was negative and dose-responsive: the poorer the respondent, the higher her risk for CA-AMR. Fourth, if bacteriuria was present, income was still a robust predictor of ESBL, suggesting that the income-AMR gradient is not driven exclusively by living conditions that would place the poor at higher risk for any bacteriuria; rather, the poor are at higher risk specifically for CA-ESBL.

Theoretical arguments could be made for a link between higher income, antimicrobial consumption, and AMR. Yet, in the context of this study, when comparing across patients within a given public healthcare system that serves all regardless of their ability to pay, we found the opposite: a negative relationship between income and CA-AMR. There are several possible explanations for this finding. First, the poor might not be able to afford the highest quality antimicrobial drugs and may rely instead on expired pills or counterfeit brands, thereby increasing exposure to subinhibitory concentrations of antimicrobial drugs that fuel the emergence of drug-resistant strains (29). Second, impoverished persons are more likely to be poorly nourished and thus exposed to infectious diseases, increasing their demand for antimicrobial drugs relative to the wealthy. Given the low prevalence of nonvitamin tablet ingestion (an upper bound on use of oral antimicrobial drugs) in our data, however, these hypotheses seem less likely. Third, the higher prevalence of AMR among poorer persons could be due to contamination. This possibility also seems an unlikely explanation because the isolates we would consider to be members of the skin microbiota (e.g., staphylococcal and streptococcal species) were distributed evenly among the high- and low-income brackets.

The most likely explanation, therefore, appears to be that the poor are exposed to an environmental source of antimicrobial drugs that is placing them at higher risk for CAAMR than their wealthier peers, resulting in the CA-AMR wealth gradient that we observed. In Hyderabad, where we conducted this study, other researchers have noted levels of many antimicrobial drugs in wastewater treatment plants and treatment plant effluents, including ciprofloxacin, that are several-fold higher than maximal therapeutic plasma levels $(25,30,31)$.

Hindu religion was also marginally significant and protective in some of our specifications, but because our income measures are noisy, this variable may also be picking up relative socioeconomic status; in our sample, Hindu women reported higher mean incomes and higher education levels than women of other religious backgrounds. The differences seem unlikely to be related to diet because strict vegetarianism was not protective.

This study had some limitations. We gathered data at a single hospital in Hyderabad, India; results may differ in other impoverished communities with different environmental exposures and in wealthier populations. In addition, survey responses were self-reported and therefore subject to measurement error and surveyor demand bias; however, it is unclear how this fact might affect the relationship between income and AMR if women did not know their urine results when they answered the survey questions. Future research should attempt to verify some of the self-reported replies and use household consumption survey data in addition to estimates of income to measure poverty (32). Further, for reasons related to cultural sensitivity and logistical feasibility, we did not collect fecal samples, and such samples might have revealed different relationships than the urine samples did. In addition, because the study was performed at a large public hospital, we observed only the lower tail of the income distribution. Data from private hospitals that cater to the wealthy might show different patterns and, combined with our data from the public sector, 

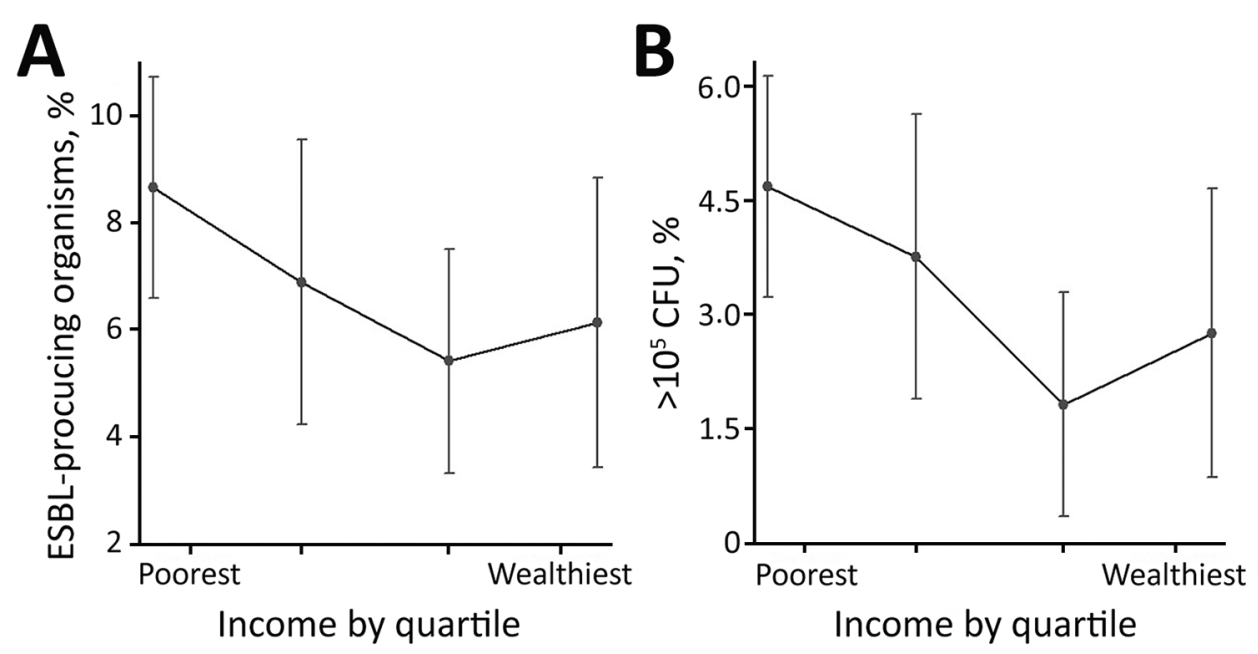

Figure 2. Nonparametric relationships between significant bacterial growth in urine culture and income $(A)$ and between community-acquired antimicrobial resistance with ESBL and income (B) for pregnant women in Hyderabad, India, adjusted for respondent age, education level, income, religious background, hospitalization in previous 12 months, and previous abortion. Dots indicate adjusted mean predicted outcome; error bars indicate $95 \% \mathrm{Cls}$. Tick marks along baselines indicate quartiles of income. ESBL, extended-spectrum $\beta$-lactamase.

might reveal a more robust U-shaped relationship between income and AMR in India. Finally, we identified 2 isolates of Sphingomonas spp., organisms commonly found in a variety of nonhost environments and occasionally identified as nosocomial pathogens (2) or as pathogens in pregnant women (33). One of the isolates was highly resistant to antimicrobial drugs, including all carbapenems in the study. The isolates did not have the same resistance pattern, however, so it is unlikely that these 2 cases were linked.

Our study has several implications for policy. To date, recommendations for reducing CA-AMR often focus on reducing selective pressure for AMR emergence, including limiting outpatient antimicrobial prescriptions, in accordance with well-established research demonstrating the link between antimicrobial drug use and AMR $(34,35)$. Our findings suggest that this recommendation may be insufficient when applied to the poorest of the poor in urban settings in developing countries. If the factors correlated with poverty, including environmental antimicrobial drug exposures, increase risk for AMR in these women, then a policy response should focus on identifying and mitigating such exposures. Future research should seek confirmation of our results in other community-dwelling populations, mapping potential hotspots of CA-AMR among the urban poor and identifying causative factors.

M.A. had full access to all of the data in the study and takes responsibility for the integrity of the data and the accuracy of the data analysis. Design and conduct of the study: M.A., A.K., N.K., J.L., D.R., and D.K.O. Collection, management, analysis, and interpretation of the data: M.A., A.K., N.K., D.K.O., D.A.R., and J.L. Preparation, review, and approval of the manuscript: all authors.

Financial support for this research was provided by the Global Development and Poverty Initiative of the Stanford Freeman
Spogli Institute for International Studies and the Graduate School of Business. The funding source had no role in the design, analyses, interpretation of the data, or decision to publish this study. D.A.R. is supported by the Thomas C. and Joan M. Merigan Endowment at Stanford University and the Chan-Zuckerberg Biohub.

\section{About the Author}

Dr. Alsan is an assistant professor of medicine at the Stanford University School of Medicine and a core faculty member at the Center for Health Policy and the Center for Primary Care and Outcomes Research. She is board-certified in both internal medicine and infectious disease and is currently an infectious disease specialist with the Department of Veterans Affairs, Palo Alto, California.

\section{References}

1. PLOS Medicine Editors. Antimicrobial resistance: is the world unprepared? PLoS Med. 2016;13: 10-12. http://dx.doi.org/10.1371/ journal.pmed.1002130

2. World Health Organization. Antimicrobial resistance: global report on surveillance. 2014 [cited 2018 May 15]. http://www.who.int/ drugresistance/documents/surveillancereport/en/

3. The Review on Antimicrobial Resistance. Antimicrobial resistance: tackling a crisis for the health and wealth of nations. 2014 [cited 2018 May 15]. https://amr-review.org/sites/default/ files/AMR $\% 20$ Review\%20Paper\%20-\%20Tackling\%20a\% 20 crisis $\% 20$ for $\% 20$ the $\% 20$ health $\% 20$ and $\% 20$ wealth $\% 20$ of $\%$ 20nations_1.pdf

4. Okeke IN, Laxminarayan R, Bhutta ZA, Duse AG, Jenkins P, O'Brien TF, et al. Antimicrobial resistance in developing countries. Part I: recent trends and current status. Lancet Infect Dis. 2005; 5:481-93. http://dx.doi.org/10.1016/S1473-3099(05)70189-4

5. Okeke IN, Klugman KP, Bhutta ZA, Duse AG, Jenkins P, O'Brien TF, et al. Antimicrobial resistance in developing countries. Part II: strategies for containment. Lancet Infect Dis. 2005;5:568-80.

6. Byarugaba DK. A view on antimicrobial resistance in developing countries and responsible risk factors. Int J Antimicrob Agents. 2004;24:105-10. http://dx.doi.org/10.1016/j.ijantimicag. 2004.02.015 
7. Stevens P. Diseases of poverty and the $90 / 10$ gap. London: International Policy Network; 2004.

8. Arcilla MS, van Hattem JM, Bootsma MC, van Genderen PJ, Goorhuis A, Schultsz C, et al. The carriage of multiresistant bacteria after travel (COMBAT) prospective cohort study: methodology and design. BMC Public Health. 2014;14:410. http://dx.doi.org/10.1186/1471-2458-14-410

9. Tängdén T, Cars O, Melhus A, Löwdin E. Foreign travel is a major risk factor for colonization with Escherichia coli producing CTX-M-type extended-spectrum $\beta$-lactamases: a prospective study with Swedish volunteers. Antimicrob Agents Chemother. 2010;54:3564-8. http://dx.doi.org/10.1128/AAC.00220-10

10. Akram M, Shahid M, Khan AU. Etiology and antibiotic resistance patterns of community-acquired urinary tract infections in J N M C Hospital, Aligarh, India. Ann Clin Microbiol Antimicrob. 2007;6:4. http://dx.doi.org/10.1186/1476-0711-6-4

11. Tankhiwale SS, Jalgaonkar SV, Ahamad S, Hassani U. Evaluation of extended spectrum beta lactamase in urinary isolates. Indian $\mathrm{J}$ Med Res. 2004;120:553-6.

12. Sun L, Klein EY, Laxminarayan R. Seasonality and temporal correlation between community antibiotic use and resistance in the United States. Clin Infect Dis. 2012;55:687-94. http://dx.doi.org/10.1093/cid/cis509

13. Austin DJ, Kristinsson KG, Anderson RM. The relationship between the volume of antimicrobial consumption in human communities and the frequency of resistance. Proc Natl Acad Sci U S A. 1999;96:1152-6. http://dx.doi.org/10.1073/pnas.96.3.1152

14. Goossens H, Ferech M, Vander Stichele R, Elseviers M; European Surveillance of Antimicrobial Consumption Project Group. Outpatient antibiotic use in Europe and association with resistance: a cross-national database study. Lancet. 2005;365:579-587.

15. Rodríguez-Baño J, Picón E, Gijón P, Hernández JR, Ruíz M, Peña C, et al.; Spanish Network for Research in Infectious Diseases (REIPI). Community-onset bacteremia due to extended-spectrum $\beta$-lactamase-producing Escherichia coli: risk factors and prognosis. Clin Infect Dis. 2010;50:40-8. http://dx.doi.org/10.1086/649537

16. Laxminarayan R, Duse A, Wattal C, Zaidi AK, Wertheim HF, Sumpradit N, et al. Antibiotic resistance - the need for global solutions. Lancet Infect Dis. 2013;13:1057-98. http://dx.doi.org/ 10.1016/S1473-3099(13)70318-9

17. Grossman M. On the concept of health capital and the demand for health. J Polit Econ. 1972;80:223-55. http://dx.doi.org/ $10.1086 / 259880$

18. Laxminarayan R, Chaudhury RR. Antibiotic resistance in India: drivers and opportunities for action. PLoS Med. 2016;13:e1001974. http://dx.doi.org/10.1371/journal.pmed.1001974

19. Okeke IN, Lamikanra A. Quality and bioavailability of tetracycline capsules in a Nigerian semi-urban community. Int J Antimicrob Agents. 1995;5:245-50. http://dx.doi.org/10.1016/0924-8579 (94)00064-2

20. Alsan M, Schoemaker L, Eggleston K, Kammili N, Kolli P, Bhattacharya J. Out-of-pocket health expenditures and antimicrobial resistance in low-income and middle-income countries: an economic analysis. Lancet Infect Dis. 2015;15:120310. http://dx.doi.org/10.1016/S1473-3099(15)00149-8

21. Onwujekwe O, Kaur H, Dike N, Shu E, Uzochukwu B, Hanson K, et al. Quality of anti-malarial drugs provided by public and private healthcare providers in south-east Nigeria. Malar J. 2009;8:22. http://dx.doi.org/10.1186/1475-2875-8-22

22. Bate R, Tren R, Mooney L, Hess K, Mitra B, Debroy B, et al. Pilot study of essential drug quality in two major cities in India.
PLoS One. 2009;4:e6003. http://dx.doi.org/10.1371/ journal.pone. 0006003

23. Sahoo KC, Tamhankar AJ, Sahoo S, Sahu PS, Klintz SR, Lundborg CS. Geographical variation in antibiotic-resistant Escherichia coli isolates from stool, cow-dung and drinking water. Int J Environ Res Public Health. 2012;9:746-59. http://dx.doi.org/10.3390/ijerph9030746

24. Nordstrom L, Liu CM, Price LB. Foodborne urinary tract infections: a new paradigm for antimicrobial-resistant foodborne illness. Front Microbiol. 2013;4:29. http://dx.doi.org/10.3389/ fmicb.2013.00029

25. Johnning A, Moore ERB, Svensson-Stadler L, Shouche YS, Larsson DG, Kristiansson E. Acquired genetic mechanisms of a multiresistant bacterium isolated from a treatment plant receiving wastewater from antibiotic production. Appl Environ Microbiol. 2013;79:7256-63. http://dx.doi.org/10.1128/ AEM.02141-13

26. US Agency for International Development. Out-of-pocket health expenditures module. 2013 [cited 2018 May 15]. https://www.dhsprogram.com/pubs/pdf/DHSQMP/DHS6_Module_ Out-of-pocket_Health_Expenditures_1Feb2013_DHSQMP.pdf

27. US Agency for International Development. Antimicrobial resistance module for population-based surveys. 2008 [cited 2018 May 15]. http://www.dhsprogram.com/What-We-Do/Survey-Types/ upload/AMR_Mod_8_5_8_FINAL.pdf

28. Lipsitch M, Bergstrom CT, Levin BR. The epidemiology of antibiotic resistance in hospitals: paradoxes and prescriptions. Proc Natl Acad Sci U S A. 2000;97:1938-43. http://dx.doi.org/10.1073/ pnas.97.4.1938

29. Andersson DI, Hughes D. Microbiological effects of sublethal levels of antibiotics. Nat Rev Microbiol. 2014;12:465-78. http://dx.doi.org/10.1038/nrmicro3270

30. Larsson DGJ, de Pedro C, Paxeus N. Effluent from drug manufactures contains extremely high levels of pharmaceuticals. J Hazard Mater. 2007;148:751-5. http://dx.doi.org/10.1016/ j.jhazmat.2007.07.008

31. Lübbert C, Baars C, Dayakar A, Lippmann N, Rodloff AC, Kinzig M, et al. Environmental pollution with antimicrobial agents from bulk drug manufacturing industries in Hyderabad, South India, is associated with dissemination of extended-spectrum beta-lactamase and carbapenemase-producing pathogens. Infection. 2017;45:479-91. http://dx.doi.org/10.1007/s15010-017-1007-2

32. Deaton A. Measuring poverty. In: Banerjee A, Bénabou R, Mookherjee D, eds. Understanding poverty. Oxford: Oxford Scholarship Online; 2006. p. 10.

33. Del Borgo C, Maneschi F, Belvisi V, Morelli F, Vetica A, Marocco R, et al. Postpartum fever in the presence of a fibroid: Sphingomonas paucimobilis sepsis associated with pyomyoma. BMC Infect Dis. 2013;13:574. http://dx.doi.org/10.1186/ 1471-2334-13-574

34. Costelloe C, Metcalfe C, Lovering A, Mant D, Hay AD. Effect of antibiotic prescribing in primary care on antimicrobial resistance in individual patients: systematic review and meta-analysis. BMJ. 2010;340:c2096. http://dx.doi.org/10.1136/bmj.c2096

35. Ghafur A, Mathai D, Muruganathan A, Jayalal JA, Kant R, Chaudhary D, et al. The Chennai declaration: a roadmap to tackle the challenge of antimicrobial resistance. Indian J Cancer. 2013;50:71-3. http://dx.doi.org/10.4103/0019-509X.104065

Address for correspondence: Marcella Alsan, Stanford University School of Medicine, 117 Encina Commons, Stanford, CA 94305, USA; malsan@stanford.edu 